\title{
EDITORIAL
}

\section{Focus on fluid therapy in critically ill patients}

\author{
Anders Perner ${ }^{1 *}$ (D) Peter B. Hjortrup ${ }^{2}$ and Yaseen Arabi ${ }^{3}$ (B)
}

C 2019 Springer-Verlag GmbH Germany, part of Springer Nature

Decisions on fluid therapy are everyday business in critically care settings. While some of these decisions remain difficult, recent years have given us better data to support better care.

Finding the right balance between giving too little intravenous (IV) fluid and giving too much remains a major challenge with potential dire consequences for our patients $[1,2]$. In the recent REFRESH pilot trial, early IV fluid restriction was feasible in patients with suspected sepsis and hypotension in the emergency department (ED) who had received $1 \mathrm{~L}$ of IV fluid [3]. As per protocol more patients in the fluid restrictive group received a vasopressor in the ED and did so earlier. The clinical and patient-important outcome measures did not differ between the intervention groups, but the trial was not powered for these and few events occurred in the lower risk population that ended up being recruited [3]. De-resuscitation strategies in the form of more aggressive fluid removal after stabilisation is also increasingly studied as an alternative approach to limit the potential negative consequences of fluid overload. In the forced fluid removal in acute kidney injury (FFAKI) trial [4], ICU patients with AKI and fluid accumulation of $>10 \%$ ideal bodyweight were randomized to fluid removal with furosemide and/or continuous renal replacement therapy aiming at net negative fluid balance $>1 \mathrm{~mL} / \mathrm{kg}$ ideal body weight/hour. While recruitment was difficult due to low numbers of patients with $>10 \%$ fluid accumulation, the intervention resulted in markedly reduced fluid balance at day five as compared to the standard care group without obvious harm [4]. These data are support by observational data from the role of active de-resuscitation after resuscitation (RADAR) investigators [5]. In

\footnotetext{
*Correspondence: anders.perner@regionh.dk

${ }^{1}$ Department of Intensive Care, Rigshospitalet, University of Copenhagen, Copenhagen, Denmark
}

Full author information is available at the end of the article a retrospective cohort study from 10 UK and Canadian ICUs, negative fluid balance achieved in the context of de-resuscitation was associated with improved survival in adults receiving invasive mechanical ventilation for at least $24 \mathrm{~h} \mathrm{[5].} \mathrm{In} \mathrm{contrast,} \mathrm{a} \mathrm{secondary} \mathrm{adjusted} \mathrm{analysis}$ of the RENAL trial suggested that high net ultrafiltration rate obtain by continuous venovenous hemodiafiltration was associated with lower survival in critically ill patients with acute kidney injury [6]. As for the studies above, residual confounding may be difficult to control for in observational data of fluid therapy and removal.

Together the above data add to a recent meta-analysis of randomised trials, the results of which indicate no benefits of more liberal vs. more conservative fluid management after the initial resuscitation, but reduced time on the ventilator was observed with conservative fluid management [7]. While the Surviving Sepsis Campaign bundles still include a fixed volume of $30 \mathrm{~mL} / \mathrm{kg}$ of IV crystalloid in early sepsis management [8], several large trials are currently assessing the overall benefit vs. harm of lower vs. higher fluid volumes during the resuscitation of patients with sepsis. Both the CLOVERS trial (NCT03434028) [9] and the CLASSIC trial (NCT03668236) are actively recruiting patients with septic shock who are being randomised to strategies aiming at lower vs. higher IV-fluid input during initial handling.

A part of the challenge is that we have not yet found a diagnostic marker that may predict the circulatory response to IV fluid in most critically ill patients. Single values of central venous pressure have repeated been shown to be of little use, latest using data from the ARISE trial on goal-directed therapy in sepsis resuscitation in the ED [10]. Echocardiographic parameters are increasingly used, but they are not fully validated and often difficult to use in complex ICU patients [11]. In any case, the fluid volumes used for resuscitation is only a small proportion (6.5\%) of the total fluid input, at least in those patients who stay in ICU for some days as observed in a retrospective single-centre study [12]. The

\section{Springer}


largest proportion of fluid was given as maintenance and replacement fluids adding up to $25 \%$ of all inputs during an average ICU stay of 6 days. Another way to facilitate lower fluid volume resuscitation is to use concentrated human albumin solutions [13]. In the recent randomised small volume resuscitation with $20 \%$ albumin in intensive care: physiological effects (SWIPE) trial of adult ICU patients requiring fluid resuscitation, the use of $20 \%$ albumin resulted in lower cumulative resuscitation fluid volume and lower cumulative fluid balance at $48 \mathrm{~h}$ as compared with the use of $4-5 \%$ albumin [14]. There were no or minor differences between the two interventions groups in urinary output, blood pressures or blood values; the maximum albumin level was higher in the $20 \%$ vs. the $4-5 \%$ albumin group. Among the more patient-important outcomes, there were no marked differences between the group, but the number of patients discharged alive from the ICU may have been higher in the albumin group. In patients treated with extracorporeal membrane oxygenation (ECMO), the use of albumin was associated with improved survival in a retrospective, single-centre, registry study [15]. Clearly, such observations come at high risk of bias, and the results should be confirmed in an RCT with lowest possible risk of bias. If albumin is beneficial, the effects may be beyond the macrocirculation; albumin use may be associated with improve endothelial dysfunction as compared to saline in a small controlled study of patients with septic shock [16].

The choice between the crystalloid solutions, i.e. isotonic saline vs. buffered solutions, also remains a challenge. Recent data from the Isotonic Solutions and Major Adverse Renal Events Trial (SMART) suggested that the acetate-gluconate-buffered solution Plasmalyte $^{\mathrm{TM}}$ resulted in a lower incidence of major adverse kidney events as compared to isotonic saline in adult ICU patients [17]. The interpretation of the SMART trial is hampered by the single-centre, open-label cluster cross-over design. At least two large trials using individual patient randomisation to Plasmalyte ${ }^{\mathrm{TM}}$ vs. saline in ICU is on the way (BASICS (NCT02875873) from Brazil and PLUS from Australasia (NCT02721654)). Added together, these three large trials will inform us on the overall balance between benefit vs. harm of the use of saline vs. buffered solutions. They will not inform us on the benefits and harms of the use of acetate-buffered vs. lactate-buffered crystalloid solutions in critically ill patients-a question that now should receive focus to improve the use of IV-fluids in critically ill patients [18].

\footnotetext{
Author details

${ }^{1}$ Department of Intensive Care, Rigshospitalet, University of Copenhagen, Copenhagen, Denmark. ${ }^{2}$ Department of Anaesthesia and Intensive Care,
}

Zealand University Hospital, Køge, Denmark. ${ }^{3}$ King Abdullah International Medical Research Center and Intensive Care Department, King Abdulaziz Medical City, College of Medicine, King Saud Bin Abdulaziz University for Health Sciences, Riyadh, Kingdom of Saudi Arabia.

\section{Compliance with ethical standards}

\section{Conflicts of interest}

The Department of Intensive Care, Rigshospitalet receives support for research from Ferring Pharmaceuticals and the Novo Nordisk Foundation.

\section{Publisher's Note}

Springer Nature remains neutral with regard to jurisdictional claims in published maps and institutional affiliations.

Received: 3 May 2019 Accepted: 17 July 2019

Published online: 25 July 2019

\section{References}

1. Perner A, Cecconi M, Cronhjort M, Darmon M, Jakob SM, Pettila V, van der Horst ICC (2018) Expert statement for the management of hypovolemia in sepsis. Intensive Care Med 44:791-798

2. Reuter DA, Chappell D, Perel A (2018) The dark sides of fluid administration in the critically ill patient. Intensive Care Med 44:1138-1140

3. Macdonald SPJ, Keijzers G, Taylor DM, Kinnear F, Arendts G, Fatovich DM, Bellomo R, McCutcheon D, Fraser JF, Ascencio-Lane JC, Burrows S, Litton E, Harley A, Anstey M, Mukherjee A, Investigators Rt (2018) Restricted fluid resuscitation in suspected sepsis associated hypotension (REFRESH): a pilot randomised controlled trial. Intensive Care Med 44:2070-2078

4. Berthelsen RE, Perner A, Jensen AK, Rasmussen BS, Jensen JU, Wiis J, Behzadi MT, Bestle MH (2018) Forced fluid removal in intensive care patients with acute kidney injury: the randomised FFAKI feasibility trial. Acta Anaesthesiol Scand 62:936-944

5. Silversides JA, Fitzgerald E, Manickavasagam US, Lapinsky SE, Nisenbaum R, Hemmings N, Nutt C, Trinder TJ, Pogson DG, Fan E, Ferguson AJ, McAuley DF, Marshall JC (2018) Role of active deresuscitation after resuscitation I deresuscitation of patients with iatrogenic fluid overload is associated with reduced mortality in critical illness. Crit Care Med 46:1600-1607

6. Murugan R, Kerti SJ, Chang CH, Gallagher M, Clermont G, Palevsky PM, Kellum JA, Bellomo R (2019) Association of net ultrafiltration rate with mortality among critically ill adults with acute kidney injury receiving continuous venovenous hemodiafiltration: a secondary analysis of the randomized evaluation of normal vs augmented level (RENAL) of renal replacement therapy trial. JAMA Netw Open 2:e195418

7. Silversides JA, Major E, Ferguson AJ, Mann EE, McAuley DF, Marshall JC, Blackwood B, Fan E (2017) Conservative fluid management or deresuscitation for patients with sepsis or acute respiratory distress syndrome following the resuscitation phase of critical illness: a systematic review and meta-analysis. Intensive Care Med 43:155-170

8. Levy MM, Evans LE, Rhodes A (2018) The surviving sepsis campaign bundle: 2018 update. Intensive Care Med 44:925-928

9. SelfWH, Semler MW, Bellomo R, Brown SM, deBoisblanc BP, Exline MC, Ginde AA, Grissom CK, Janz DR, Jones AE, Liu KD, Macdonald SPJ, Miller CD, Park PK, Reineck LA, Rice TW, Steingrub JS, Talmor D, Yealy DM, Douglas IS, Shapiro NI, Committee CP, Prevention N, Early Treatment of Acute Lung Injury Network I (2018) Liberal versus restrictive intravenous fluid therapy for early septic shock: rationale for a randomized trial. Ann Emerg Med 72:457-466

10. Reddi B, Finnis M, Udy AA, Maiden M, Delaney A, Bellomo R, Peake S, Committee ASM, New Zealand Intensive Care Society Clinical Trials G (2018) The relationship between the change in central venous pressure and intravenous fluid volume in patients presenting to the emergency department with septic shock. Intensive Care Med 44:1591-1592

11. Vieillard-Baron A, Evrard B, Repesse X, Maizel J, Jacob C, Goudelin M, Charron C, Prat G, Slama M, Geri G, Vignon P (2018) Limited value of endexpiratory inferior vena cava diameter to predict fluid responsiveness impact of intra-abdominal pressure. Intensive Care Med 44:197-203 
12. Van Regenmortel $N$, Verbrugghe $W$, Roelant $E$, Van den Wyngaert $T$, Jorens PG (2018) Maintenance fluid therapy and fluid creep impose more significant fluid, sodium, and chloride burdens than resuscitation fluids in critically ill patients: a retrospective study in a tertiary mixed ICU population. Intensive Care Med 44:409-417

13. Zampieri FG, Hjortrup PB (2018) Moving albumin into the small volume resuscitation era. Intensive Care Med 44:1967-1969

14. Martensson J, Bihari S, Bannard-Smith J, Glassford NJ, Lloyd-Donald P, Cioccari L, Luethi N, Tanaka A, Crisman M, Rey de Castro N, Ottochian M, Huang A, Cronhjort M, Bersten AD, Prakash S, Bailey M, Eastwood GM, Bellomo R (2018) Small volume resuscitation with 20\% albumin in intensive care: physiological effects: the SWIPE randomised clinical trial. Intensive Care Med 44:1797-1806

15. Wengenmayer T, Schroth F, Biever PM, Duerschmied D, Benk C, Trummer G, Kaier K, Bode C, Staudacher DL (2018) Albumin fluid resuscitation in patients on venoarterial extracorporeal membrane oxygenation (VAECMO) therapy is associated with improved survival. Intensive Care Med 44:2312-2314

16. Hariri G, Joffre J, Deryckere S, Bige N, Dumas G, Baudel JL, Maury E, Guidet B, Ait-Oufella H (2018) Albumin infusion improves endothelial function in septic shock patients: a pilot study. Intensive Care Med 44:669-671

17. Semler MW, Self WH, Wanderer JP, Ehrenfeld JM, Wang L, Byrne DW, Stollings JL, Kumar AB, Hughes CG, Hernandez A, Guillamondegui OD, May AK, Weavind L, Casey JD, Siew ED, Shaw AD, Bernard GR, Rice TW, Investigators S, the Pragmatic Critical Care Research G (2018) Balanced crystalloids versus saline in critically ill adults. N Engl J Med 378:10

18. Ellekjaer KL, Jensen MM, Perner A, Moller MH (2019) Lactate versus acetate buffered crystalloid solutions: protocol for a scoping review. Acta Anaesthesiol Scand 63:537-539 